\title{
In vitro histomorphometric comparison of dental pulp tissue in different teeth
}

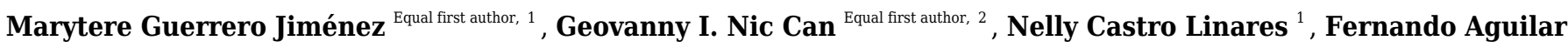 \\ Ayala ${ }^{1}$, Michel Canul Chan ${ }^{3}$, Rafael Rojas Herrera ${ }^{4}$, Ricardo Peñaloza Cuevas ${ }^{1}$, Beatriz A. Rodas Junco ${ }^{\text {Corresp. } 2}$ \\ 1 Laboratorio Traslacional de Células Troncales de la Cavidad Bucal, Facultad de Odontología, Universidad Autónoma de Yucatán, Mérida, Yucatán, México \\ 2 CONACYT-Facultad de Ingeniería Química, Universidad Autónoma de Yucatán, Mérida, Yucatán, México \\ 3 Facultad de Ciencias Químicas, Universidad Veracruzana, Orizaba, Veracruz, México \\ 4 Facultad de Ingeniería Química, Universidad Autónoma de Yucatán, Mérida, Yucatán, México \\ Corresponding Author: Beatriz A. Rodas Junco \\ Email address: beatriz.rodas@correo.uady.mx
}

Background. Dental pulp (DP) represents an accessible and valuable source promising of stem cells for clinical application. However, there are some disadvantages associated with the isolation of dental pulp stem cells (DPSCs), which include the size and weight of the pulp tissue needed to yield sufficient cells for culturing in vitro. Therefore, the objective of this study was to compare in vitro histomorphometry of DP from permanent (premolars, third molar), supernumerary and deciduous teeth of patients between 5 and 25 years old with regards to weight, length, width and the cell density in the four regions of the DP in order to obtain quantitative parameters in a tissue that represents a valuable source of stem cells. Methods. DPs were obtained from 10 central incisors deciduous, 20 permanent teeth (10 premolars, 10 third molars) and 10 supernumeraries ( 6 mesiodents and 4 inferior premolar shapes). The pulps were carefully removed, and the entire tissue was weighed. The pulp length and the width were measured withadigital Vernier caliper. The cellular density analysis was performed according to the four regions of the DP (coronal, cervical, medial and apical) in histological slides using photography and the ImageJ ${ }^{\circledR}$ program for quantification. Results. The Pearson correlation test revealed that DP weight among different types of teeth is correlated with age in male patients. A significant positive correlation was noted between length and width of the DP with age in both genders. The mean DP weight for supernumerary and third molar teeth was greater than deciduous and premolar teeth. Finally, the histological analysis showed that the coronal and apical portions of DP in supernumerary and premolar teeth have the highest cell density. Conclusions. The DP of supernumerary teeth has quantitatively the best morphometric parameters and cell density comparable with the quality of DP obtained from deciduous teeth. 
1

2

3

4

5

6

7

8

9

\title{
IN VITRO HISTOMORPHOMETRIC COMPARISON OF DENTAL PULP TISSUE IN DIFFERENT TEETH
}

\author{
Marytere Guerrero-Jiménez ${ }^{1}$, Geovanny Nic-Can ${ }^{1,2}$, Nelly Castro-Linares ${ }^{1}$, Fernando Aguilar- \\ Ayala ${ }^{1}$, Michel Canul-Chan ${ }^{3}$, Rafael Rojas Herrera ${ }^{4}$, Ricardo Peñaloza-Cuevas ${ }^{1}$ and Beatriz A. \\ Rodas-Junco ${ }^{1,2 *}$ \\ ${ }^{1}$ Laboratorio Traslacional de Células Troncales de la Cavidad Bucal, Facultad de Odontología, \\ Universidad Autónoma de Yucatán, Mérida, México.
}

${ }^{2}$ CONACYT-Facultad de Ingeniería Química, Universidad Autónoma de Yucatán, Mérida, Yucatán, México.

${ }^{3}$ Facultad de Ciencias Químicas, Universidad Veracruzana, Orizaba, Veracruz, México.

${ }^{4}$ Facultad de Ingeniería Química, Universidad Autónoma de Yucatán, Mérida, Yucatán, México.

${ }^{*}$ Corresponding author: Beatriz A. Rodas-Junco².

${ }^{2}$ CONACYT - Facultad de Ingeniería Química, Universidad Autónoma de Yucatán, Mérida, Yucatán, México.

Email address: beatriz.rodas@,correo.uady.mx; barodasju@conacyt.mx

\section{Abstract:}

Background. Dental pulp (DP) represents an accessible and valuable source promising of stem cells for clinical application. However, there are some disadvantages associated with the isolation of dental pulp stem cells (DPSCs), which include the size and weight of the pulp tissue needed to yield sufficient cells for culturing in vitro. Therefore, the objective of this study was to compare in vitro histomorphometry of DP from permanent (premolars, third molar), supernumerary and deciduous teeth of patients between 5 and 25 years old with regards to weight, length, width and 
26 the cell density in the four regions of the DP in order to obtain quantitative parameters in a tissue

27 that represents a valuable source of stem cells.

28 Methods. DPs were obtained from 10 central incisors deciduous, 20 permanent teeth (10

29 premolars, 10 third molars) and 10 supernumeraries (6 mesiodents and 4 inferior premolar

shapes). The pulps were carefully removed, and the entire tissue was weighed. The pulp length

and the width were measured with a digital Vernier caliper. The cellular density analysis was

performed according to the four regions of the DP (coronal, cervical, medial and apical) in

histological slides using photography and the ImageJ ${ }^{\circledR}$ program for quantification.

Results. The Pearson correlation test revealed that DP weight among different types of teeth is correlated with age in male patients. A significant positive correlation was noted between length and width of the DP with age in both genders. The mean DP weight for supernumerary and third molar teeth was greater than deciduous and premolar teeth. Finally, the histological analysis showed that the coronal and apical portions of DP in supernumerary and premolar teeth have the highest cell density.

Conclusions. The DP of supernumerary teeth has quantitatively the best morphometric parameters and cell density comparable with the quality of DP obtained from deciduous teeth.

\section{Introduction}

Dental pulp (DP) is an innervated, highly vascularized soft tissue that provides vitality to the tooth (Rodas-Junco et al. 2017). DP is located inside each primary or permanent tooth, and its main functions include the generation of dentine and maintenance of its biological and physiological vitality in response to traumatic injuries, physical stimulus or bacterial infections (Marrelli et al.

47 2018; Ravindra et al. 2015; Tatullo et al. 2015). The regenerative function of DP suggests that it contains odontogenic progenitor cells or stem cells that are involved in the regeneration process. 
49 In this context, DP has drawn attention in dental research as an accessible and valuable source of

50 stem cells known as dental pulp stem cells (DPSCs). Moreover, DPSCs are going to be ideal for

51 tissue engineering and regenerative medicine (Chalisserry et al. 2017; Honda et al. 2017; Ledesma-

52 Martínez et al. 2016). However, there are some disadvantages associated with the isolation of

53 DPSCs, which might be directly related to the size and weight of DP tissue by limiting the number

54 of stem cells isolated from it (Raoof et al. 2014). Besides, some studies have also focused on

55 methods to correlate some morphometric parameter of the pulp tissue with the patient's age. For

56 example, Ravindra et al. (2015) observed through intra-oral radiography that the total area of the

57 pulp decreased with age. Other authors focus on establishing regression equations using the

58 number of cells in DP to also predict age (Hossain et al. 2017; Von Böhl et al. 2016). Conversely,

59 until now there are no reports that relate morphometric parameters such as weight, length, width

60 and cellular density of DP among different types of teeth and its influence on tissue quality for the

61 isolation of DP cells. Therefore, the objective of this study was to compare the histomorphometry

62 of DP in temporal and permanent teeth and evaluate the cell density in four regions in this tissue

63 with to purpose of generating quantitative parameters that would have important applications in

64 the DPSCs isolation.

65

\section{Materials \& Methods}

\section{Patient recruitment and tooth storage}

68 The DP tissue was obtained from 10 deciduous central incisors, 20 permanent teeth (10 premolars,

6910 third molars) and 10 supernumeraries (6 mesiodents and 4 inferior premolar shape). An

70 informed patient consent was obtained from patients or parents of minors. The collection of the

71 material was performed at the Clinics of the Master in Pediatric Dentistry and Oral Surgery, 
72 Faculty of Dentistry, Autonomous University of Yucatan. The age of patients ranged from 5 to 25

73 years, and a slight prevalence of females $(21 / 40,55.5 \%)$ was noted. The protocol was approved

74 by the Ethics Research Committee of Hideyo Noguchi Regional Research Center, Autonomous

75 University of Yucatán (Approval number: CIE-06-2017). The extracted deciduous teeth exhibited

76 one-third to two-thirds root resorption with well-defined roots. After extraction, all the teeth were

77 rinsed for five minutes in a conical tube containing phosphate-buffered saline (PBS 1X: $138 \mathrm{mM}$

$78 \mathrm{NaCl}, 3 \mathrm{mM} \mathrm{KCl}, 8.1 \mathrm{mM} \mathrm{Na}_{2} \mathrm{HPO}_{4}$ and $1.5 \mathrm{mM} \mathrm{KH}_{2} \mathrm{PO}_{4}, \mathrm{pH}$ 7.4) and labeled with the donor's

79 age and tooth type.

80 Tissue removal and processing

81 The teeth were immersed in sterile phosphate buffer saline (PBS 1X pH 7.4), stored on ice pack

82 and transported to the cell culture lab for sample processing. After cleaning the surface of the tooth,

83 a vertical cut of the dental organ was performed using a rotary electric micro motor (String®) with

84 a diamond disc (diameter: $22 \mathrm{~mm}$ and thickness: $0.4 \mathrm{~mm}$; ATK $®$ ). During this process, constant

85 irrigation was maintained with cold PBS $1 \mathrm{X} \mathrm{pH} 7.4$ to reduce overheating of dental tissue (Fig.

86 1A-C). Thereafter, the entire pulp tissue was carefully extracted from the cavities of the tooth using

87 a metal clamp and it was weighed using an analytical balance (Citizen CX 200) (Fig. 1D). The

88 pulp length and width were measured with a digital Vernier caliper with a $0.01 \mathrm{~mm}$ calibration.

89 Histomorphometry

90 The pulp tissues were fixed in 10\% formaldehyde solution. Subsequently, the DP was dehydrated

91 in increasing concentration of alcohol: 60, 70, 80 and 100\%. After that, the DPs were embedded

92 in paraffin and dissected in sections of $5 \mu \mathrm{m}$ of thickness with a sliding microtome (Leica

93 LM2500). The slices were then dewaxed and stained with hematoxylin and eosin. Four histology

94 slides from each tooth were selected for analysis. Images of the pulp were captured through the 
95

96

97 98 digital microscope at a resolution of $1280 \times 720$ (Leica DM750 camera MC170H) and 4-100x magnifications connected to a computer. A cell counting was performed manually under highpower (100x magnification) at four regions of each DP tissue: coronal, cervical, middle and apical. For each cell population, the number of cells was normalized to the total area of the pulp sample $(325 \mu \mathrm{m} \times 402 \mu \mathrm{m})$. Afterwards, each image obtained from the histology slides were analyzed by ImageJ v1.49 Software.

\section{Statistical analysis}

A one-factor analysis of variance with Tukey's post hoc test was used. The Pearson correlation coefficient was calculated to determine the correlation between morphometric measurements of the dental pulp and the relationship with the patient's age. Statistical significance was defined as $\mathrm{p} \leq 0.05$.

\section{Results}

\section{Correlation between morphometric measurements of the dental pulp and patients' age}

A correlation study was undertaken to examine the weight, length and width of DP with patients' age (Fig. 2A-F). The DP weight was correlated with age in male patients, whereas significant changes $(\mathrm{p} \leq 0.05)$ were not noted in females (Fig. 2A and B). The Pearson correlation test revealed a significant positive $(\mathrm{p} \leq 0.05)$ correlation between length and width of the DP with age in both genders (Fig. 2C-F). In general, the data showed that the DP obtained from males had a greater weight, length and width compared with that from females. The results indicate an optimal age interval in males (15-20 years) and females (20-25 years) to obtain $10 \mathrm{mg}$ of DP. 
118 Comparison of morphometric measurements of dental pulp among different types of teeth

119 Linear data correlation and one-factor variance analyses were applied to the variables of weight,

120 length and width (Table 1). The weight of DP was significantly increased $(\mathrm{p} \leq 0.05)$ in

121 supernumerary teeth $(20.5 \pm 3.56 \mathrm{mg})$ and third molars $(18.7 \pm 11.5 \mathrm{mg})$ from male patients

122 compared with those from females. In contrast, the mean differences in length and width

123 measurements of DP in the third molars were highly significant $(\mathrm{p} \leq 0.05)$ compared with the other

124 types of teeth in both genders (Table 1).

125 Comparison of dental pulp histology and cellular density of dental pulp tissue in different 126 types of teeth

127 Due the DP of the different teeth analyzed showed different morphometric measurements, we 128 hypothesized that the density in the cell-rich zone may also be different. Thus, a histological 129 analysis was performed in coronal, cervical, middle and apical regions of the DP to evaluate the 130 cell density (Fig. 3A-N). The histological evaluation revealed a three-layer structure consisting of 131 a layer of odontoblasts (OB; Fig. 3A-N, yellow arrowhead) with regularly arranged columnar cells 132 in the contour of the pulp and a dispersed layer of cells in all DP samples. Conversely, in the 133 subodontoblastic zone (SOB), a thin and cell-free layer zone (CFZ; Fig. 3A-N, green arrowhead) was observed. The cell-rich zone (CRZ; Fig. 3A-N, red arrowhead) showed a dense layer of cells per unit, especially in fibroblasts and undifferentiated mesenchymal cells that continue in the central zone of the pulp, in which the presence of blood vessels (BV), nerve fibers (NV) and connective tissue (CT) is highlighted (Fig 3A-N). The DP of the supernumeraries presented a limited presence of NV (Fig. 3I-L) compared with the pulp obtained from the premolars, third molars and deciduous. The histology of the pulp in the coronal and cervical regions of deciduous 
140 teeth showed an irregular shape, making layers difficult to identify during staining with

141 hematoxylin and eosin (Fig. 3M and N).

142 A greater cellular density was observed in the coronal region of deciduous and premolar teeth

143 compared with supernumerary and third molars (Table 2). In contrast, a high cell density was

144 observed in the apical region of supernumeraries and premolars compared with third molar teeth

145 (Table 2). Together, these results indicate that the apical region of the DP in supernumerary and 146 premolar teeth potentially represents the ideal location to obtain cells.

\section{Discussion}

148 Knowledge of DP histomorphometry in teeth is important for identifying the tooth type that could 149 provide the best source of cells. Several researchers have focused on obtaining DPSCs from 150 exfoliated deciduous or permanent third molars because stem cells from these teeth exhibit a high

151 proliferation capacity (Daud et al. 2016; Shekar and Ranganathan 2012). It is therefore necessary

152 to identify other source of DPs with quality cellular characteristics for the isolation of cells. In the

153 literature, reports on morphometric and histological measurements of the DP regions among 154 temporary and permanent teeth are quite limited. Besides, pulp weight is a parameter that few 155 authors have considered to obtain DPSCs (Alsulaimani et al. 2016; Kellner et al. 2014; Singh et 156 al. 2016). Our research group considers that DP weight could be important as a starting point for

157 the isolation of DPSCs. The results of the present study show that the DP weight was greater in 158 the supernumerary and third molars teeth in male patients compared with female patients (Table 159 1). The weight observed in supernumerary (mesiodents) teeth was may be due to the dense fibrous 160 DP, which could indicate a greater amount of organic substance in this tooth type. The third molar 161 DP of females exhibited an increased weight compared with males likely because female DP was 162 obtained from upper teeth with fused roots. This characteristic facilitated the procurement of a 
163 larger homogenous pulp tissue compared with males whose third molars were primarily from the 164 mandible and with separated roots. In 1999, (Méndez and Zarzoza) reported a mean weight pulp 165 of $13.10 \pm 4.33 \mathrm{mg}$ in eight premolars fragmented with a hammer. In our study, we used a vertical 166 cutting method to obtain DP from all types of teeth. This variation in weight could be explained 167 by the fact that the fractionation by impact could lead to the loss of pulp tissue. In addition, some 168 premolars had separated roots, so the size of the pulp tissue may reduce.

169 On the other hand, it is also important to note that the DP also undergoes age-related changes, and 170 several studies have focused on aging. Recently, Kellner et al. (2014) determined that the relation 171 between pulp vs. hard tooth tissue in third molar decreases with aging. This finding was also 172 observed in our study (Fig. 2). Unfortunately, no reports on deciduous pulp weight were found to 173 compare our observations.

174 The length of DP was three-fold higher in permanent compared with deciduous teeth (Table 1) 175 because deciduous teeth showed a physiological reabsorption that does not occur in permanent 176 teeth. Regarding DP width, measurements of deciduous and permanent teeth are obtained using 177 radiological techniques, such as pericapical X-rays or orthopantomography. For example, Kazmi 178 et al. (2017) used conventional radiology to measure the mesio-distal crown width of deciduous 179 teeth in males and females, revealing no significant differences, which was consistent with our 180 findings (Table 1). However, there are no reports about the in vitro length of the pulp for 181 comparison with our results. On the other hand, the cell-rich zone contains progenitor cells that 182 exhibit plasticity and pluripotency. For instance, (Lizier et al. 2012) indicated that DPSCs are 183 located in multiple niches, which are associated with capillaries and the nerve network of the 184 central region in the CRZ and in the outer layer of pulp tissue (Graziano et al. 2008; Pagella et al. 185 2015). We observed that the apical region of the DP of the supernumerary teeth, showed a higher 
186 cell density compared to the other permanent teeth. Interestingly, in the total analysis of cell 187 density, the supernumerary teeth have similar cellular density compared to deciduous teeth (Table 188 2). Although the pulp tissue of the deciduous teeth was smaller, this pulp exhibited the highest cell 189 density compared with the other dental organs (Table 2). This finding could be explained because 190 the coronal and apical regions are held together after a physiological resorption in deciduous teeth.

191 Gronthos et al. (2002) showed that the DP derived from lower deciduous central incisors contains 192 a large number of cells able to form adherent colonies similar to mesenchymal stem cells in in 193 vitro culture. In contrast, the small number of cells available for isolation due to the size of the 194 pulp, especially in exfoliated deciduous teeth represents a potential problem with obtaining DPSCs 195 (Marrelli et al. 2018). Thus, one of the advantages of supernumerary teeth for the isolation of cells 196 is that these teeth are extracted at an early age, which apparently retain embryogenic characteristics 197 as demonstrated for another source of stem cells from the oral cavity (Dunaway et al. 2017). These 198 results indicate that supernumerary teeth in patients between 5-20 years of age have the best 199 morphometric parameters. However, the determination of the biological properties such as proliferation and differentiation potential of the isolated cells in the different regions of this tissue requires further studies.

\section{Conclusions}

In this study, in vitro histomorphometric comparison and cellular density of the DP from temporary and permanent teeth of patients from 5 to 25 years of age were addressed. It was shown that supernumerary DP has the best morphometric parameters and its cell density is comparable to that of deciduous tooth pulp. This phenomenon has not been described before and could have important applications in the isolation of stem cells in this tissue.

\section{Acknowledgements}

Peer] reviewing PDF | (2019:04:36933:2:0:NEW 4 Nov 2019) 
Program for manuscript editing.

212

213

214

215

216

217

218

219

220

221

222

223

224

225

226

227

228

229

230

231

232

233

234

235

236

237

238

239

240

241

242

243

244

245

246

247

248

249

250

251

\section{References}

Alsulaimani RS, Ajlan SA, Aldahmash AM, Alnabaheen MS, and Ashri NY. 2016. Isolation of dental pulp stem cells from a single donor and characterization of their ability to differentiate after 2 years of cryopreservation. Saudi medical journal 37:551-560. 10.15537/smj.2016.5.13615

Chalisserry EP, Nam SY, Park SH, and Anil S. 2017. Therapeutic potential of dental stem cells. Journal of tissue engineering 8:2041731417702531-2041731417702531. 10.1177/2041731417702531

Daud S, Nambiar P, Hossain MZ, Rahman MRA, and Bakri MM. 2016. Changes in cell density and morphology of selected cells of the ageing human dental pulp. Gerodontology 33:315-321. 10.1111/ger.12154

Dunaway K, Goorha S, Matelski L, Urraca N, Lein PJ, Korf I, Reiter LT, and LaSalle JM. 2017. Dental pulp stem cells model early life and imprinted DNA methylation patterns. Stem Cells 35:981-988.

Graziano A, d'Aquino R, Laino G, and Papaccio G. 2008. Dental Pulp Stem Cells: A Promising Tool for Bone Regeneration. Stem Cell Reviews 4:65-65. 10.1007/s12015-008-9015-3

Gronthos S, Brahim J, Li W, Fisher LW, Cherman N, Boyde A, DenBesten P, Robey PG, and Shi S. 2002. Stem Cell Properties of Human Dental Pulp Stem Cells. Journal of Dental Research 81:531-535. $10.1177 / 154405910208100806$

Honda M, Sato M, and Toriumi T. 2017. Characterization of Coronal Pulp Cells and Radicular Pulp Cells in Human Teeth. Journal of Endodontics 43:S35-S39. 10.1016/j.joen.2017.06.005

Hossain MZ, Daud S, Nambiar P, Razak FA, Ab-Murat N, Saub R, and Bakri MM. 2017. Correlation between numbers of cells in human dental pulp and age: Implications for age estimation. Archives of Oral Biology 80:51-55. https://doi.org/10.1016/j.archoralbio.2017.03.018

Kazmi S, Anderson P, and Liversidge HM. 2017. A radiographic study of pulp crown dimensions of the mandibular deciduous second molar. International Journal of Dentistry and Oral Health.

Kellner M, Steindorff MM, Strempel JF, Winkel A, Kühnel MP, and Stiesch M. 2014. Differences of isolated dental stem cells dependent on donor age and consequences for autologous tooth replacement. Archives of Oral Biology 59:559-567. https://doi.org/10.1016/j.archoralbio.2014.02.014

Ledesma-Martínez E, Mendoza-Núñez VM, and Santiago-Osorio E. 2016. Mesenchymal Stem Cells Derived from Dental Pulp: A Review. Stem cells international 2016:4709572-4709572. 10.1155/2016/4709572

Lizier NF, Kerkis A, Gomes CM, Hebling J, Oliveira CF, Caplan AI, and Kerkis I. 2012. Scaling-up of dental pulp stem cells isolated from multiple niches. PloS one 7:e39885-e39885. 10.1371/journal.pone.0039885 
Marrelli M, Codispoti B, Shelton RM, Scheven BA, Cooper PR, Tatullo M, and Paduano F. 2018. Dental Pulp Stem Cell Mechanoresponsiveness: Effects of Mechanical Stimuli on Dental Pulp Stem Cell Behavior. Frontiers in physiology 9:1685-1685. 10.3389/fphys.2018.01685

Méndez JD, and Zarzoza E. 1999. Rapid determination of dry weight in human dental pulp by a colorimetric reaction. Journal of Endodontics 25:596-598. https://doi.org/10.1016/S0099-2399(99)80315-X

Pagella P, Neto E, Lamghari M, and Mitsiadis TA. 2015. Investigation of orofacial stem cell niches and their innervation through microfluidic devices. Eur Cell Mater 29:213-223.

Raoof M, Yaghoobi MM, Derakhshani A, Kamal-Abadi AM, Ebrahimi B, Abbasnejad M, and Shokouhinejad N. 2014. A modified efficient method for dental pulp stem cell isolation. Dental research journal 11:244-250.

Ravindra SV, Mamatha GP, Sunita JD, Balappanavar AY, and Sardana V. 2015. Morphometric analysis of pulp size in maxillary permanent central incisors correlated with age: An indirect digital study. Journal of forensic dental sciences 7:208-214. 10.4103/0975-1475.172438

Rodas-Junco BA, Canul-Chan M, Rojas-Herrera RA, De-la-Peña C, and Nic-Can GI. 2017. Stem Cells from Dental Pulp: What Epigenetics Can Do with Your Tooth. Frontiers in physiology 8:999-999. 10.3389/fphys.2017.00999

Shekar R, and Ranganathan K. 2012. Phenotypic and growth characterization of human mesenchymal stem cells cultured from permanent and deciduous teeth. Indian Journal of Dental Research 23:838.

Singh N, Verma UP, Chowdhury R, Mishra A, and Sahu DK. 2016. Enumeration and Characterization of Mesenchymal Stem Cells from Age-dependent Human Dental Tissue. J Stem Cell Res Ther 6:2.

Tatullo M, Marrelli M, Shakesheff KM, and White LJ. 2015. Dental pulp stem cells: function, isolation and applications in regenerative medicine. Journal of tissue engineering and regenerative medicine 9:1205-1216.

Von Böhl M, Ren Y, Kuijpers-Jagtman AM, Fudalej PS, and Maltha JC. 2016. Age-related changes of dental pulp tissue after experimental tooth movement in rats. PeerJ 4:e1625. 


\section{Figure 1}

Cutting technique of vertical dental organ to obtain pulp.

(A) Cutting vertical of the dental organ using electric rotatory micro motor with diamond disc and irrigation with cold PBS 1 X pH 7.4 (B-C) Breaking-up of the tooth along the vertical axis using a metal spatula and divided into two equal halves, one mesial and the distal. (D) Isolation of the complete dental pulp tissue from the cavities of the tooth using a metal clamp. 

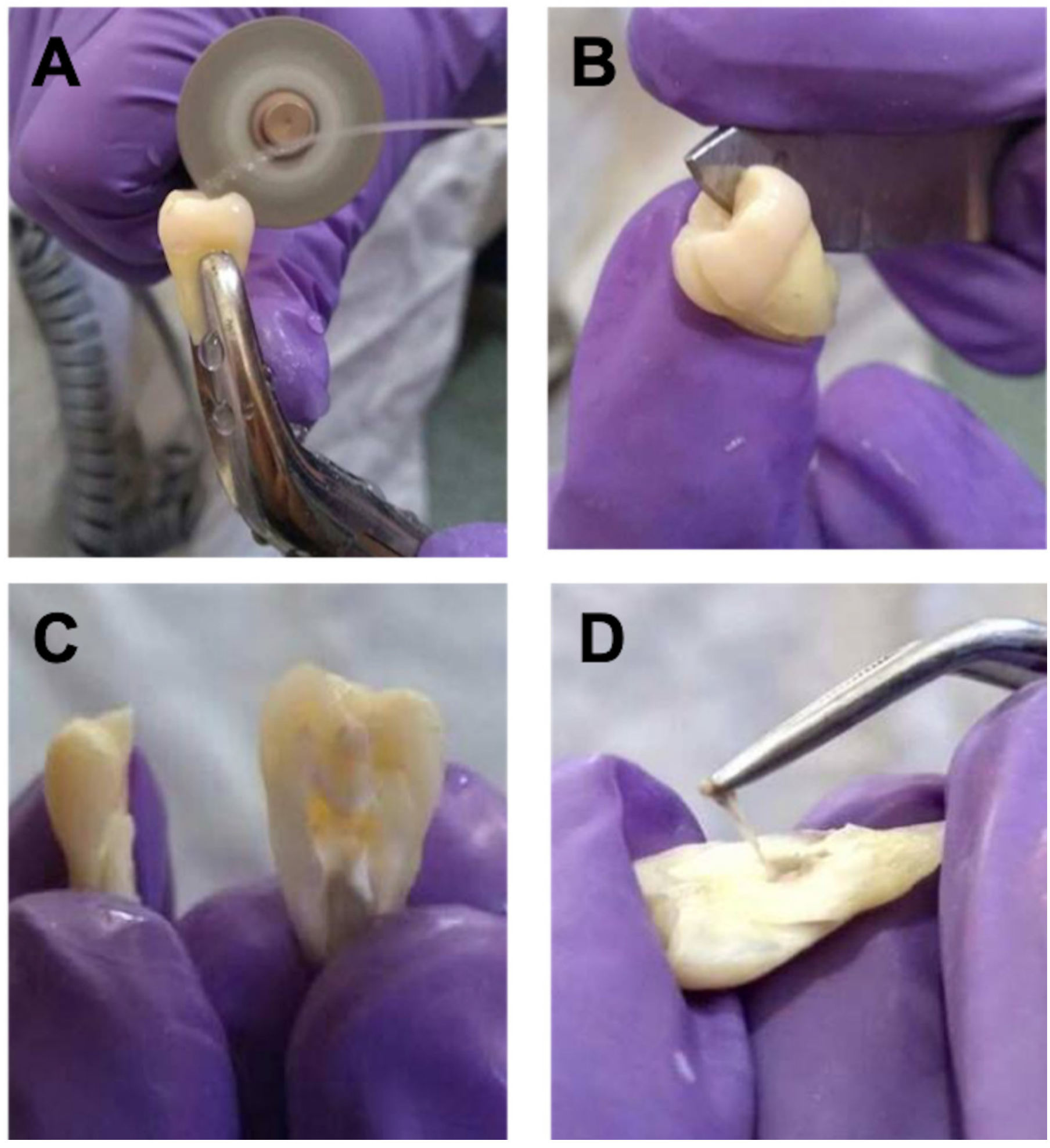


\section{Figure 2}

Correlation of weight, length and width measurements of the dental pulp and its relationship with the patient's age.

Dental pulp tissue from males and females were isolated and evaluated by (A-B) Weight, (CD) Length and (E-F) Width to determinate its correlation with the patient's age by using the Pearson correlation coefficient. Data from all of the investigated third molar, premolars, deciduous and supernumerary are shown. The value $r$ was calculated for all data at a significance level of $p \leq 0.05$. 

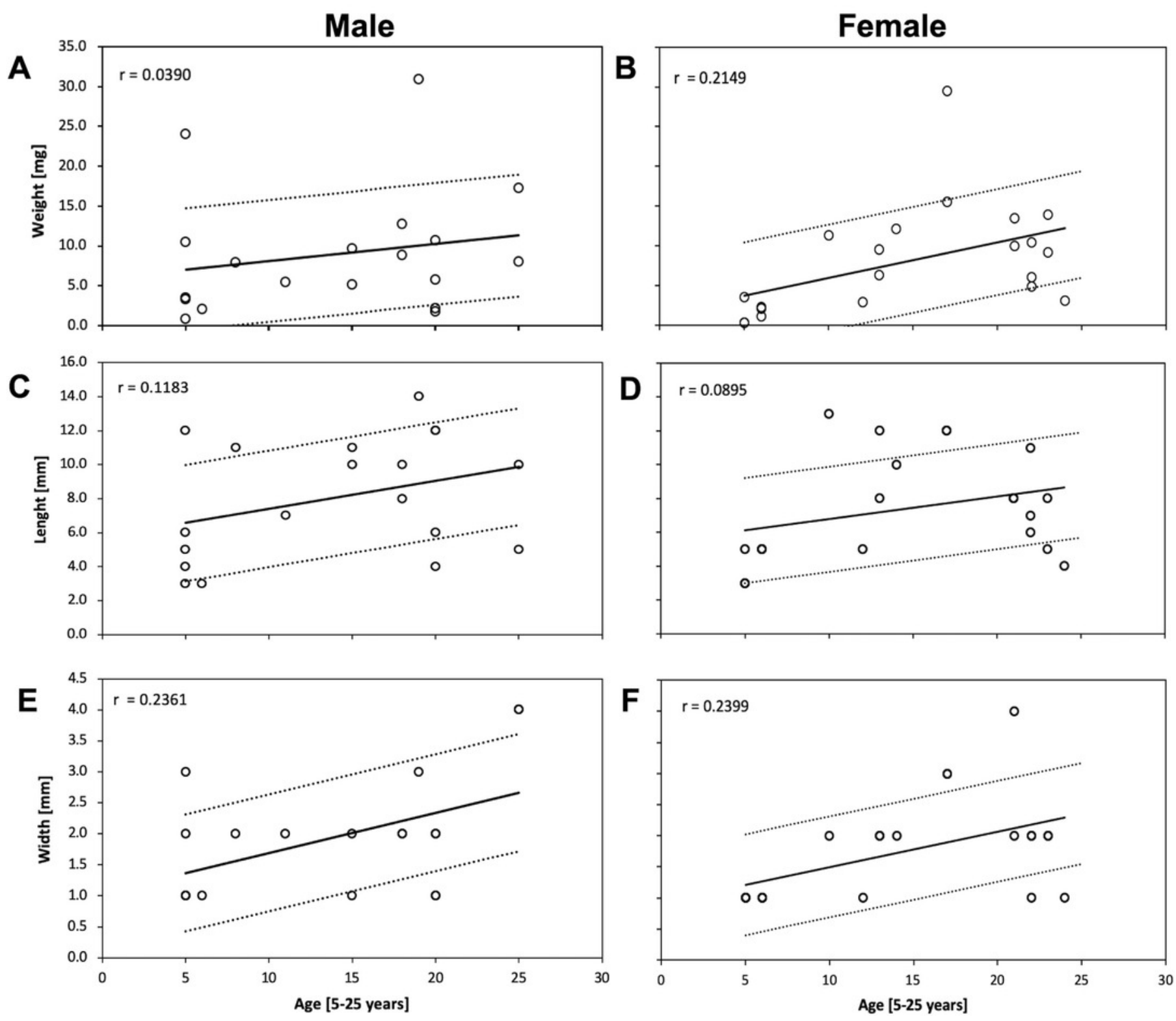


\section{Figure 3}

Photomicrographs of histologic sections of different regions in dental pulp from premolars, third molar, supernumerary and deciduous teeth.

Microscopic image demonstrating a typical tissue from (A-M) coronal, (B-N) cervical, (C-K) middle and (D-L) apical regions of dental pulp in different teeth. All sections were stained with hematoxylin and eosin. OB, odontoblast layer (yellow arrowhead); D, dentine; CFZ, cellfree zone (green arrowhead); CRZ, cell-rich zone (red arrowhead); BV, blood vessels; NF, nerve fibers, $\mathbf{D}$, dentine, $\mathbf{P}$, pulp and $\mathbf{C T}$, connective tissue. UD: denotes Not determined, this regions are not found in deciduous teeth ( $\mathbf{O}$ and $\mathbf{P}$ ).

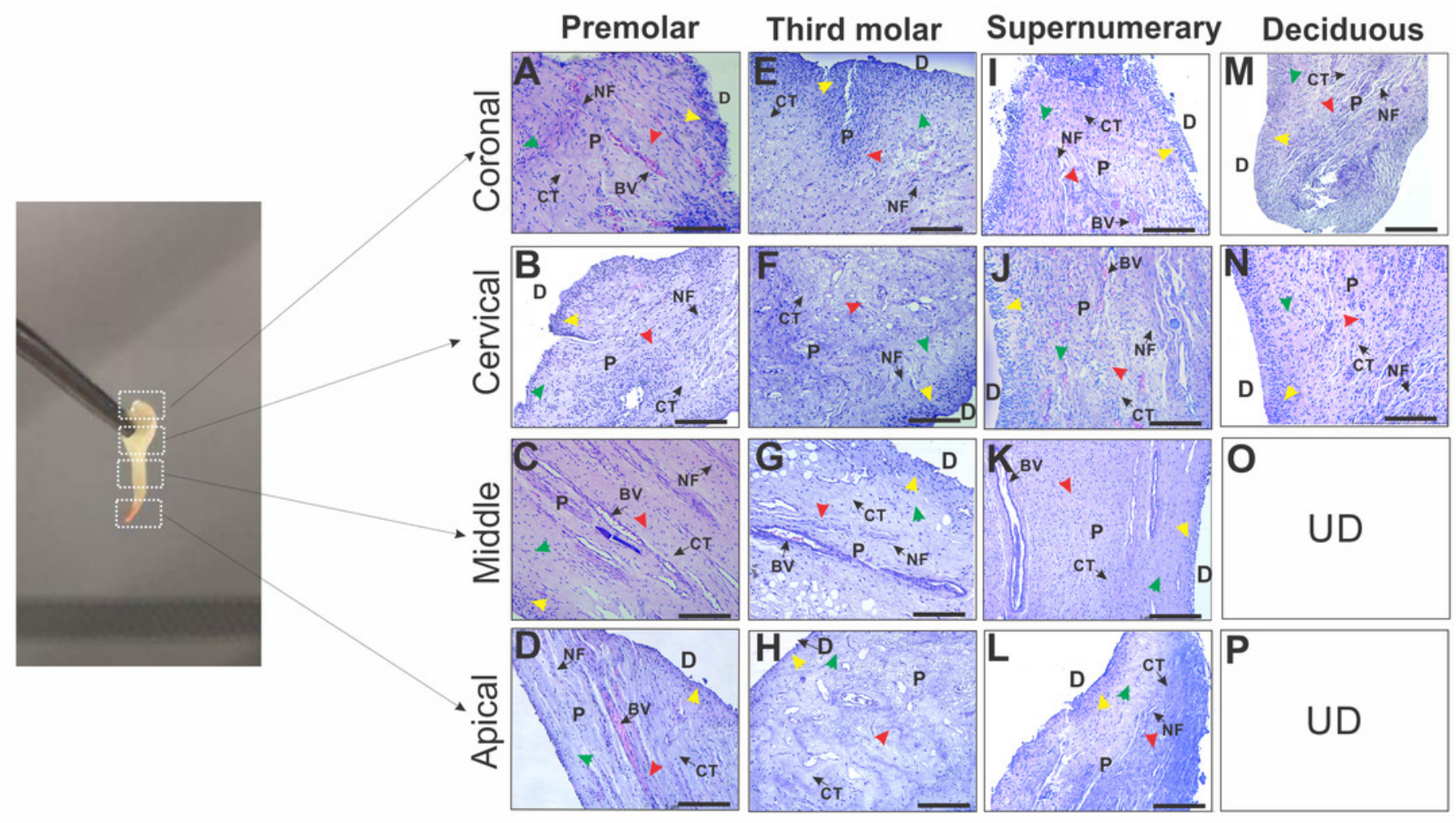




\section{Table $\mathbf{1}$ (on next page)}

Comparison of weight, length and width of dental pulp from different teeth between males and females

The values of weight, width and length of the pulp of each 10 samples per tooth type were calculated. Different letters indicate significant differences between each measurement and type of teeth. P-value $<0.05$. 
1

2

3

\begin{tabular}{|c|c|c|c|c|c|c|}
\hline \multirow{2}{*}{ Parameters } & \multicolumn{2}{|l|}{ Male } & \multicolumn{2}{|c|}{ Female } & \multicolumn{2}{|l|}{ Total } \\
\hline & Mean & SD & Mean & SD & Mean & SD \\
\hline \multicolumn{7}{|l|}{ Deciduos } \\
\hline Weigth (mg) & 2.40 & 0.011 & 1.7 & 0.0013 & 2.05 & 0.006 \\
\hline Length (mm) & 3.75 & 4.500 & 4.33 & 1.03 & $4.04^{\mathrm{a}, \mathrm{b}, \mathrm{c}}$ & 2.765 \\
\hline Width (mm) & 1.00 & 0.557 & 1.0 & 0 & $1.0^{\mathrm{c}, \mathrm{d}}$ & 0.278 \\
\hline \multicolumn{7}{|l|}{ Third molar } \\
\hline Weigth (mg) & 18.7 & 0.011 & 14.6 & 0.007 & 16.65 & 0.009 \\
\hline Length (mm) & 9.66 & 4.500 & 9.14 & 2.600 & $9.40^{\mathrm{b}}$ & 3.550 \\
\hline Width (mm) & 3.66 & 0.557 & 2.57 & 0.786 & $3.115^{\mathrm{a}, \mathrm{b}, \mathrm{c}}$ & 0.672 \\
\hline \multicolumn{7}{|l|}{ Premolar } \\
\hline Weigth (mg) & 9.10 & 0.003 & 7.1 & 0.003 & 8.10 & 0.003 \\
\hline Length (mm) & 9.75 & 1.250 & 7.83 & 2.850 & $8.79^{\mathrm{a}}$ & 2.050 \\
\hline Width (mm) & 1.75 & 0.500 & 1.66 & 0.515 & $1.705^{\mathrm{a}}$ & 0.507 \\
\hline \multicolumn{7}{|c|}{ Supernumerary } \\
\hline Weigth (mg) & 20.5 & 0.035 & 7.2 & 0.005 & 13.85 & 0.020 \\
\hline Length (mm) & 8.75 & 3.320 & 9.0 & 5.650 & $8.875^{c}$ & 4.485 \\
\hline Width (mm) & 1.87 & 0.640 & 1.5 & 0.707 & $1.685^{b, d}$ & 0.674 \\
\hline
\end{tabular}




\section{Table 2 (on next page)}

Cell density values in specific regions of dental pulp tissue from different teeth

All values were calculated from three histological sites for each one of the regions of dental pulp (DP) among the different teeth expressed as the mean \pm standard deviation. $(a, b$ and $c)$ indicate significant differences in each region of DP and the type of tooth, . (A, B, C, D and E) indicate significance between different tooth and each region of DP, $p \leq 0.05$. UD: denotes Not determined, this regions are not found in deciduous teeth. 


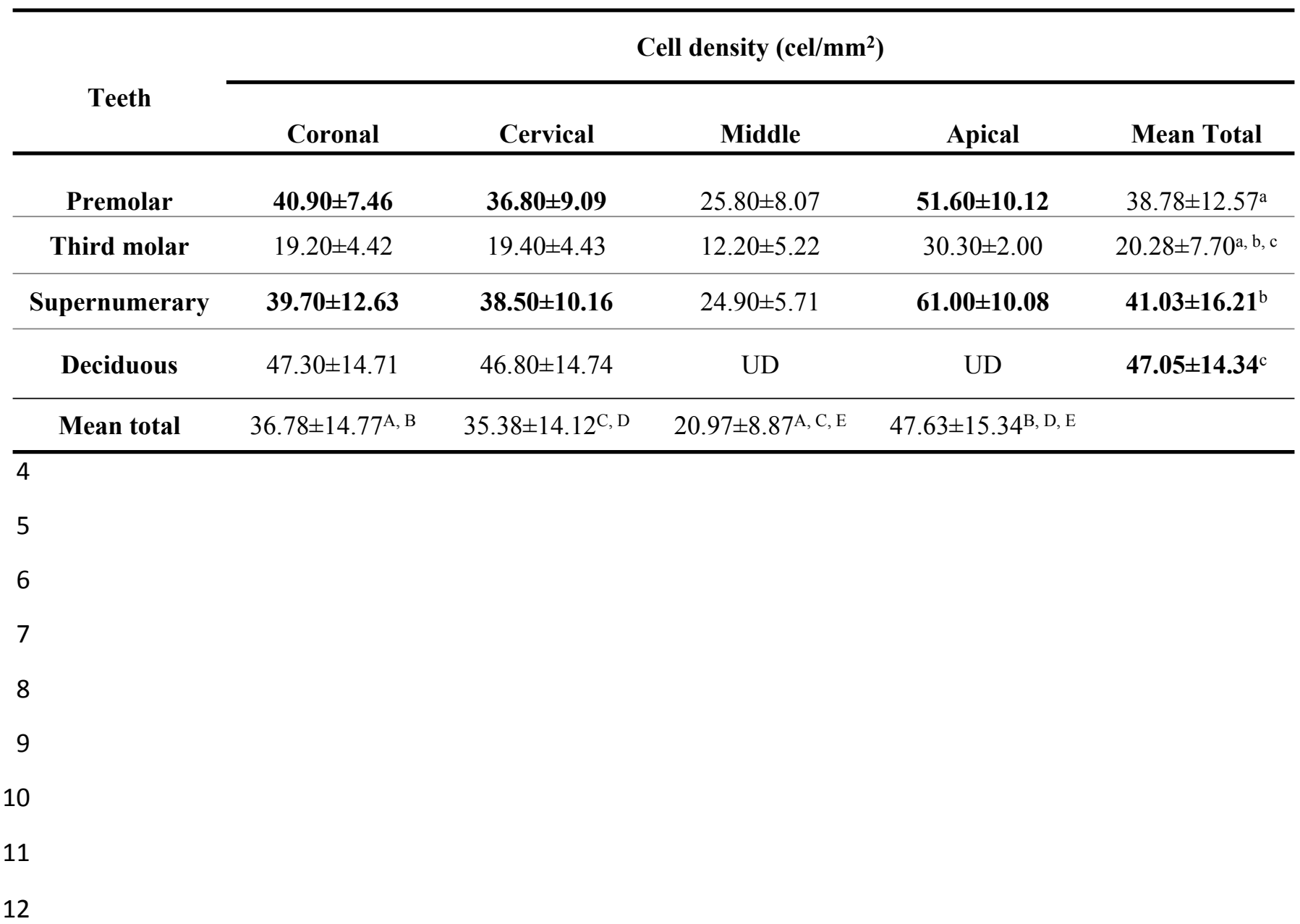

